J. Dairy Sci. 97:1961-1969

http://dx.doi.org/10.3168/jds.2013-7418

(C) American Dairy Science Association ${ }^{\circledR}, 2014$.

\title{
Glycosylation of K-casein: Genetic and nongenetic variation and effects on rennet coagulation properties of milk
}

\author{
V. Bonfatti, G. Chiarot, and P. Carnier ${ }^{1}$ \\ Department of Comparative Biomedicine and Food Science (BCA), University of Padova, viale dell'Università 16, 35020, Legnaro, Padova, Italy
}

\begin{abstract}
The aims of this study were to investigate genetic and nongenetic variation in the degree of glycosylation of $\kappa$-casein $(\kappa-\mathrm{CN})$ and to estimate the effects of glycosylated $(\mathrm{G}-\kappa \mathrm{CN})$ and unglycosylated $(\mathrm{U}-\kappa \mathrm{CN}) \kappa-\mathrm{CN}$ contents on milk coagulation properties of Simmental cows. Measures of contents of the main casein fractions, $\mathrm{G}-\kappa \mathrm{CN}$, and $\mathrm{U}-\kappa \mathrm{CN}$, and assessment of genotypes at CSN2, CSN3, and BLG were obtained by reversedphase HPLC analysis of 2,015 individual milk samples. Content of total $\kappa-\mathrm{CN}$ ( $\kappa$-CNtot, g/L) was the sum

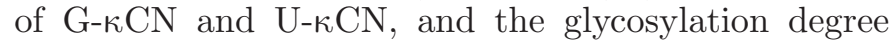
of $\kappa$-CN (GD) was measured as the ratio of $\mathrm{G}-\kappa \mathrm{CN}$ to $\kappa$-CNtot. Rennet coagulation time (RCT) and curd firmness were measured by using a computerized renneting meter. Measures of curd firmness were adjusted for RCT before statistical analysis. Variance components

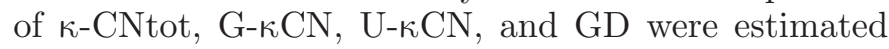
by Bayesian procedures and univariate linear models that included the class effects of the herd-test-day, parity, days in milk, genotypes at milk protein genes, and

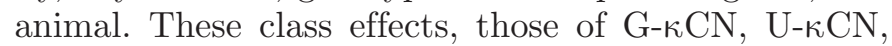
and content of other caseins, and the linear effect of milk $\mathrm{pH}$ were accounted for by models investigating the influence of $\kappa$-CN glycosylation on coagulation properties. The GD ranged from 22 to $76 \%$, indicating that variation in G- $\kappa \mathrm{CN}$ depends on the variation both in $\kappa$-CNtot and in the efficiency of $\kappa$-CN glycosylation.

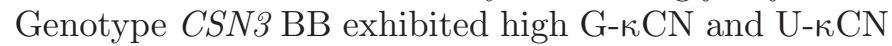
relative to that of $C S N 3$ AA. Heritability of G- $\mathrm{KCN}$, $\mathrm{U}-\kappa \mathrm{CN}$, and GD was high and ranged from 0.46 to 0.56. A large proportion of the additive genetic variation in G- $\kappa \mathrm{CN}$ and $\mathrm{U}-\kappa \mathrm{CN}$ was attributable to influence of $C S N$ and $B L G$, but these genes did not affect variation in GD, and across-genotypes differences in the trait were small or trivial. Average RCT of the milk class having the highest G- $\kappa \mathrm{CN}$ was, on average, $2 \mathrm{~min}$ (standard deviation 0.5) shorter than that of the lowest class. Conversely, U-kCN and content of other caseins
\end{abstract}

Received August 26, 2013.

Accepted December 26, 2013.

${ }^{1}$ Corresponding author: valentina.bonfatti@unipd.it were not associated with any effect on RCT, except for a slight delay in coagulation when $\mathrm{U}-\kappa \mathrm{CN}$ was very high. Curd firmness increased when the contents of both $\kappa-\mathrm{CN}$ fractions and other caseins increased. This study provides evidence that the positive association between RCT and $\kappa-\mathrm{CN}$ content is exclusively attributable to the glycosylated fraction of the protein. Because exploitable additive genetic variation in G- $\mathrm{kCN}$ exists, improvement of $\kappa-\mathrm{CN}$ composition through selective breeding might be an effective way to enhance milk coagulation properties.

Key words: casein, glycosylation, coagulation, heritability

\section{INTRODUCTION}

$\kappa$-Casein acts as a hairy layer on the casein micelle surface, providing steric and electrostatic repulsion between micelles and preventing aggregation. When approximately $85 \%$ of the $\kappa-\mathrm{CN}$ has been hydrolyzed by chymosin, micelles begin to aggregate, forming a gellike network (Fox and McSweeney, 2003). $\kappa$-Casein is the only glycosylated $\mathrm{CN}$ and multiple isoforms showing different degrees of glycosylation coexist in milk (Dziuba and Minkiewicz, 1996). Molecules of $\kappa-C N$ can have up to 9 glycans, containing galactose, $\mathrm{N}$-acetylgalactosamine, and $\mathrm{N}$-acetylneuraminic acid (NANA) or sialic acid (Vreeman et al., 1986). The release of the polar glycomacropeptide domain from $\kappa$-CN eliminates the polar electrostatic and steric stabilization of the micelle surface, with an increase in the surface hydrophobicity. This makes micelles associate, leading to clot formation (Fox and McSweeney, 2003).

Associations between CSN3 B and enhanced milk coagulation properties (MCP) or increased cheese yield have been detected (Caroli et al., 2009; Bonfatti et al., 2011). The influence of CSN3 on MCP results from across-genotype variation in the ratio of $\kappa-\mathrm{CN}$ to total CN (Bonfatti et al., 2010a). Variant CSN3 B seems to be associated with a high degree of $\kappa$-CN glycosylation relative to that of CSN3 A (Coolbear et al., 1996), but knowledge about the role of $\kappa$-CN glycosylation in determinism of milk technological properties is scarce. Glycosylation is known to affect the stabilizing activ- 


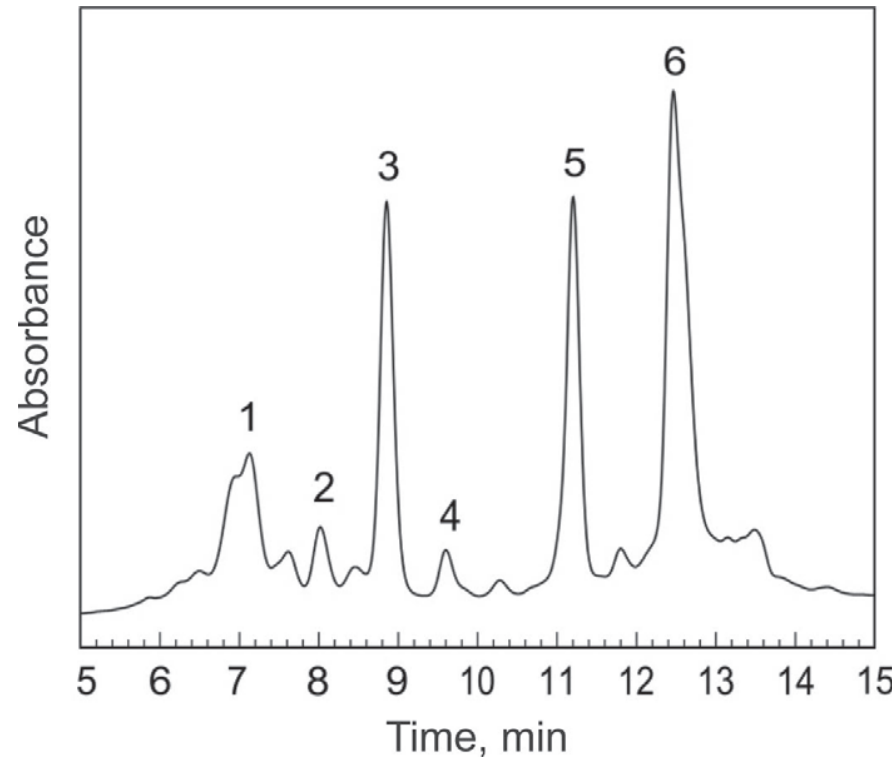

Figure 1. Chromatogram of an individual milk sample (peak 1 $=$ glycosylated form of $\mathrm{k}-\mathrm{CN}$ variants $\mathrm{A}$ and $\mathrm{B}$; peak $2=$ glycosylated form of $\kappa-\mathrm{CN}$ variant $\mathrm{A}$; peak $3=$ unglycosylated form of $\kappa-\mathrm{CN}$ variant $\mathrm{A}$; peak $4=$ glycosylated form of $\kappa-\mathrm{CN}$ variant $\mathrm{B}$; peak $5=$ unglycosylated form of $\kappa-\mathrm{CN}$ variant $\mathrm{B}$; peak $6=\alpha_{\mathrm{S}_{2}} \mathrm{CN}$ ).

ity of $\kappa$-CN toward the other caseins (Takeuchi et al., 1985), micelle size (Doi et al., 1979a), and susceptibility to chymosin proteolysis (Doi et al., 1979b; Vreeman et al., 1986) in simple model systems. The degree of $\kappa-\mathrm{CN}$ glycosylation has been hypothesized to play a role in variation in MCP (Tyrisevä et al., 2008). The aims of this study were to investigate the genetic and nongenetic variation in the degree of $\kappa$-CN glycosylation and to estimate the effects exerted by contents of glycosylated and unglycosylated $\kappa$-CN on MCP of individual milk samples.

\section{MATERIALS AND METHODS}

A detailed description of the data used in this study can be found in Bonfatti et al. (2010a,b).

\section{Milk Sampling}

Individual milk samples of 2,015 Simmental cows, reared in 47 commercial herds in the north of Italy, were collected from November 2007 to December 2008. Milk sampling occurred once per animal during the a.m. or p.m. milking, concurrently with the monthly milk recording of the herd. A preservative (bronopol, 0.6:100; vol/vol) was added to milk immediately after collection to prevent microbial growth, and the samples were stored at $-40^{\circ} \mathrm{C}$ until reversed-phase (RP)-HPLC analysis. Milk yield records and pedigree information were supplied by the Italian Simmental cattle breeders association (ANAPRI, Udine, Italy).

\section{Milk Protein Composition and Genotyping}

Contents of $\alpha_{\mathrm{S}^{-}} \mathrm{CN}, \alpha_{\mathrm{S}_{2}} \mathrm{CN}, \beta-\mathrm{CN}, \gamma-\mathrm{CN}$, glycosylated $\kappa-\mathrm{CN}(\mathbf{G}-\kappa \mathbf{C N})$ and unglycosylated $\kappa-\mathrm{CN}$ $(\mathbf{U}-\boldsymbol{\kappa} \mathbf{C N})$ of milk samples were assessed using the RP-HPLC method of Bonfatti et al. (2008). Content

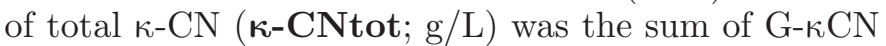
and U-kCN (Figure 1), whereas the content of other caseins $(\mathbf{O C N}, \mathrm{g} / \mathrm{L})$ was computed as the sum of $\alpha_{\mathrm{S}^{-}}$ $\mathrm{CN}, \alpha_{\mathrm{S} 2}-\mathrm{CN}, \beta-\mathrm{CN}$, and $\gamma-\mathrm{CN}$ contents. The degree of $\kappa-\mathrm{CN}$ glycosylation (GD) was measured as the ratio of G- $\kappa$ CN to $\kappa$-CNtot, not as the glycoside content of the molecules itself. Genotypes of cows at CSN2, CSN3, and $B L G$ were assayed by RP-HPLC (Bonfatti et al., 2008). Because of the very low frequency of CSN1S1 C and CSN3 E variants (Bonfatti et al., 2010b), CSN1S1 was considered to be monomorphic, and allele $\mathrm{E}$ of CSN3 was not taken into account in this study. Hence, the estimated effects of genotypes carrying CSN3 A might be slightly biased by being affected by the pooled effects of CSN3 $\mathrm{A}$ and CSN3 $\mathrm{E}$.

\section{Analysis of MCP}

A measure of milk pH (pH-Burette 24, Crison, Barcelona, Spain), rennet coagulation time (RCT) and curd firmness at 30 min after rennet addition $\left(\mathbf{A}_{\mathbf{3 0}}\right)$ was obtained for each sample. Measures of RCT and $\mathrm{A}_{30}$ were obtained through a computerized renneting meter (CRM-48, Polo Trade, Monselice, Italy) and using procedures described in Bonfatti et al. (2010a). As time for instrumental assessment of MCP was restricted to $31 \mathrm{~min}$ after the addition of rennet to samples, $\mathrm{A}_{30}$ was inherently correlated with RCT: less time was available for curd firming when coagulation time was long and, consequently, the final curd was weaker. Therefore, measures of $\mathrm{A}_{30}$ were adjusted for $\mathrm{RCT}\left(\mathbf{A d j} \mathbf{A}_{\mathbf{3 0}}\right)$ before statistical analysis. Because the relationship between $\mathrm{RCT}$ and $\mathrm{A}_{30}$ was not linear, adjustment was carried out through local regressions using the LOESS procedure of SAS (SAS Institute Inc., Cary, NC). Samples that did not coagulate within 31 min after rennet addition were classified as noncoagulating milk. Cecchinato and Carnier (2011) proposed appropriate statistical models to deal with information from noncoagulating milk. However, because the fraction of noncoagulating milk samples was small (6.3\%) and due to missing information on MCP, records of those samples were not included in the statistical analysis. 


\section{Statistical Analysis}

Variation in $\kappa-C N$ tot, G- $\kappa \mathrm{CN}, \mathrm{U}-\kappa \mathrm{CN}$, and GD was investigated by estimating genetic and nongenetic effects and variance components through univariate linear models and by using Bayesian procedures for statistical inference. The following univariate animal model was fitted to the data:

$$
\mathrm{y}_{\mathrm{ijkl}}=\mathrm{HTD}_{\mathrm{i}}+\mathrm{PAR}_{\mathrm{j}}+\mathrm{DIM}_{\mathrm{k}}+\mathrm{a}_{\mathrm{ijkl}}+\mathrm{e}_{\mathrm{ijkl}} \text {, }
$$

where $\mathrm{HTD}_{\mathrm{i}}$ is the effect of the herd-test-day $(\mathrm{i}=1$, $\ldots, 47), \mathrm{PAR}_{\mathrm{j}}$ is the effect of the parity of the cow $(\mathrm{j}=$ 1 : first, $j=2$ : second, $j=3$ : third, $j=4$ : fourth or later parities), $\mathrm{DIM}_{\mathrm{k}}$ is the effect of the DIM class (11 classes of 30-d intervals with the exception of the last class including samples collected at DIM $\geq 300$ ), $\mathrm{a}_{\mathrm{ijkl}}$ is the additive genetic effect of the animal, and $\mathrm{e}_{\mathrm{ijkl}}$ is a random residual. As an alternative, a mixed-inheritance model including, in addition to the aforementioned effects, the effects of $C S N 2, C S N 3$, and $B L G$ genotypes was fitted. Traits were assumed to be conditionally distributed as follows:

$$
\mathbf{y} \mid \mathbf{b}, \mathbf{q}, \mathbf{a}, \sigma_{e}^{2} \sim N\left(\mathbf{X b}+\mathbf{W q}+\mathbf{Z a}, \mathbf{I} \sigma_{e}^{2}\right),
$$

where $\mathbf{y}$ is a vector of individual phenotypes for a trait ( $\kappa$-CNtot, G- $\kappa \mathrm{CN}, \mathrm{U}-\kappa \mathrm{CN}$, or GD); b is an unknown vector including PAR, DIM, and, in the case of the mixed-inheritance model, CSN2, CSN3, and BLG genotype effects; $\mathbf{q}$ is an unknown vector of herd-test-day effects; $\mathbf{a}$ is an unknown vector of additive genetic effects of animals; $\sigma_{e}^{2}$ is the residual variance; $\mathbf{X}, \mathbf{W}$, and $\mathbf{Z}$ are known incidence matrices relating effects in $\mathbf{b}, \mathbf{q}$, and $\mathbf{a}$, respectively, to $\mathbf{y}$; and $\mathbf{I}$ is an identity matrix of appropriate order. Bounded uniform priors represented vague prior knowledge about effects in $\mathbf{b}$. Prior knowledge about additive genetic and herd-test-day effects was based on the assumption that these effects were normally distributed, as follows:

$$
\mathbf{q} \mid \sigma_{q}^{2} \sim N\left(\mathbf{0}, \mathbf{I} \sigma_{q}^{2}\right),
$$

where $\sigma_{q}^{2}$ is the herd-test-day variance and $\mathbf{I}$ is an identity matrix of order equal to the number of levels of herd-test-day effects; and

$$
\mathbf{a} \mid \mathbf{A} \sigma_{a}^{2} \sim N\left(\mathbf{0}, \mathbf{A} \sigma_{a}^{2}\right),
$$

where $\mathbf{A}$ is the numerator of Wright's relationship matrix and $\sigma_{a}^{2}$ is the additive genetic variance. Additive relationships in $\mathbf{A}$ were computed using a pedigree file including all phenotyped animals and their known ancestors (16,602 animals). Each sampled cow had at least 4 generations of known ancestors. Bounded uniform distributions were used as priors for variance components.

The marginal posterior densities of the unknowns in the model were estimated using Gibbs sampling. A single Gibbs chain of 500,000 samples was generated in each analysis. After a burn-in period of 50,000 iterations, 1 sample in each 250 was saved for each parameter of interest. Parameters of interest were the variance components, heritabilities, and differences between model solutions for parity, DIM class, and genotype effects. Convergence of the Gibbs chains was checked using the Z-criterion of Geweke (1992). The posterior median was used as a point estimate of parameters of concern. Lower and upper bounds of the 95\% highest posterior density interval (HPD95\%) were obtained from the estimated marginal densities. The heritability was defined as follows:

$$
h^{2}=\frac{\sigma_{a}^{2}}{\sigma_{a}^{2}+\sigma_{p}^{2}+\sigma_{e}^{2}},
$$

where $\sigma_{a}^{2}, \sigma_{p}^{2}$, and $\sigma_{e}^{2}$ are the additive genetic, herd-testday, and residual variance, respectively. For heritability, we computed also the guaranteed value of the parameter with a probability of $95 \%$ (K95\%), which was the minimum value of the heritability in the interval K95\% to 1 , corresponding to a posterior probability of $95 \%$.

Effects of $\mathrm{CN}$ and $\kappa-\mathrm{CN}$ composition (extent of glycosylation of $\kappa-\mathrm{CN}$ ) on variation in $\mathrm{MCP}$ were estimated using 2 linear models. Model [1] was used to investigate the effects of $\mathrm{CN}$ composition on MCP and included the effect of the herd-test-day, parity, DIM class, SCS class ( 6 classes of 1 point each, with the exception of the last class, which included samples with SCS $>5$ ), the linear effect of milk $\mathrm{pH}$, the class effects of OCN and $\kappa$-CNtot, and the additive genetic effect of the animal. Model [2] included the same effects as model [1] except that the class effect of $\kappa$-CNtot was replaced by the class effects of $\mathrm{G}-\kappa \mathrm{CN}$ and $\mathrm{U}-\kappa \mathrm{CN}$. In the analysis of $\mathrm{Adj}_{30}$, the effect of the computerized renneting meter measuring well (10 wells) was also included in models.

Because preliminary analyses suggested that effects of protein fraction contents on MCP were nonlinear, such effects were fitted as class effects. Contents of OCN, $\kappa-C N$ tot, $\mathrm{G}-\kappa \mathrm{CN}$, and $\mathrm{U}-\kappa \mathrm{CN}$ were classified as follows: class $\mathrm{C}--$ (content $<$ mean $-\mathrm{SD})$, class $\mathrm{C}-$ (mean $-\mathrm{SD} \leq$ content $<$ mean $-0.5 \mathrm{SD})$, class $\mathrm{C} 0$ (mean $-0.5 \mathrm{SD} \leq$ content $<$ mean $+0.5 \mathrm{SD})$, class $\mathrm{C}+$ (mean $+0.5 \mathrm{SD} \leq$ content $<$ mean $+\mathrm{SD})$, and class $\mathrm{C}++($ content $\geq$ mean $+\mathrm{SD})$. Settings for Bayesian 
Table 1. Descriptive statistics of milk protein composition and coagulation traits $(\mathrm{n}=2,015)^{1}$

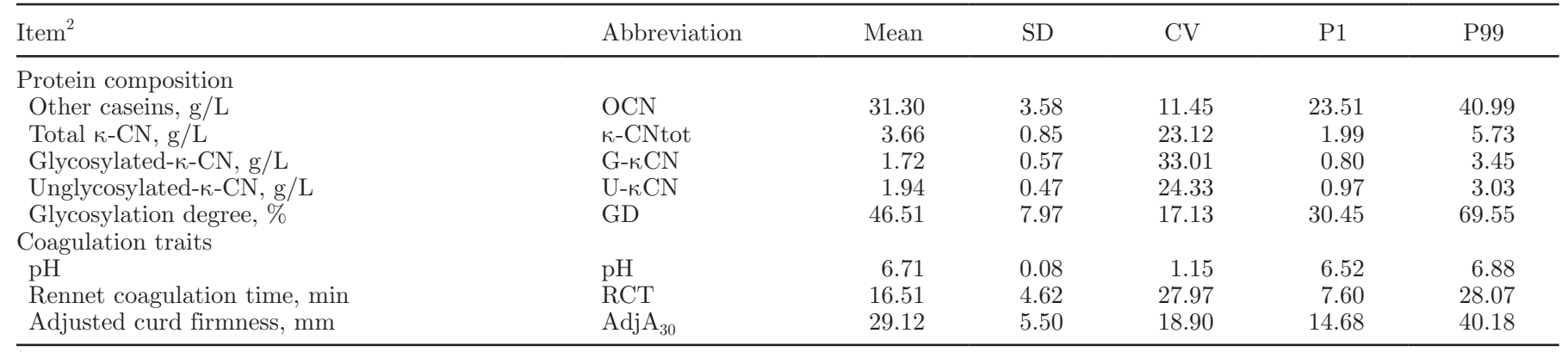

${ }^{1} \mathrm{P} 1=1$ st percentile; $\mathrm{P} 99=99$ th percentile.

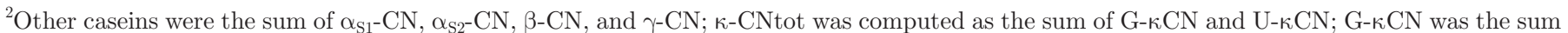

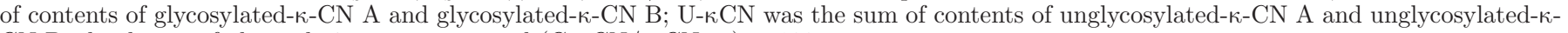
$\mathrm{CN} B$; the degree of glycosylation was computed $(\mathrm{G}-\kappa \mathrm{CN} / \kappa-\mathrm{CNt}$ tot $) \times 100$.

analyses were the same as those used in the analysis of $\kappa$-CNtot, G- $\kappa \mathrm{CN}, \mathrm{U}-\kappa \mathrm{CN}$, and GD. Bounded uniform densities were used as prior densities for the protein fractions class effects. The median, the bounds of HPD95\%, and the probability of an estimated difference of being greater (for positive estimates) or lower (for negative estimates) than 0 were obtained from the marginal posterior densities of differences between protein classes.

\section{RESULTS AND DISCUSSION}

\section{Descriptive Statistics}

Descriptive statistics for contents of milk protein fractions and MCP are reported in Table 1. In agreement with Vreeman et al. (1986) and Mollé and Léonil (1995), G- $\kappa \mathrm{CN}$ accounted for $46.5 \%$ of $\kappa$-CNtot. The degree of $\kappa-\mathrm{CN}$ glycosylation ranged from 22 to $76 \%$, indicating that variation in G- $\mathrm{\kappa CN}$ depends upon the variation in $\kappa$-CNtot as well as in the efficiency of $\kappa-\mathrm{CN}$ glycosylation during secretion. Variation in $\kappa-\mathrm{CN}$ composition has been described also by Robitaille et al. (1993) and Coolbear et al. (1996), but recent studies
(Holland et al., 2004, 2005; Jensen et al., 2012a) suggested a more consistent pattern of $\kappa-\mathrm{CN}$ posttranslational modifications than that found in our study.

\section{Parity and DIM Effects on $\mathrm{k}-\mathrm{CN}$ Composition}

Estimates of parity effects on variation in $\kappa-\mathrm{CN}$ fraction contents are reported in Table 2. The degree of glycosylation increased from first to second parity and then slowly decreased in later parities. This result is not consistent with findings of Robitaille et al. (1991), who noticed a marked decrease in the NANA content of $\kappa-\mathrm{CN}$ with increasing parity number.

Variation in $\kappa-\mathrm{CN}$ fraction content across DIM classes is depicted in Figure 2. The content of $\kappa$-CNtot and G- $\mathrm{KCN}$ slightly decreased in early lactation, until the time of peak milk yield, and then increased in mid

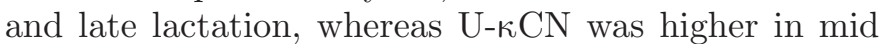
lactation and slightly decreased thereafter. Lodes et al. (1996) reported no significant variation in $\mathrm{U}-\kappa \mathrm{CN}$ during lactation, resulting in a marked increase of GD from d 150 of lactation, which is consistent with the variation in the NANA content of $\kappa-\mathrm{CN}$ during lactation observed by Robitaille et al. (1991).

Table 2. Estimate (Est, SD units of the trait) and $95 \%$ highest posterior density region (HPD95\%) of the effect of parity, compared with the

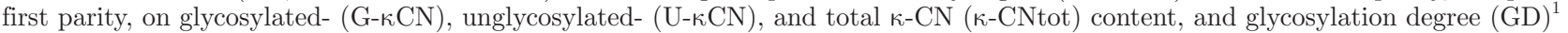

\begin{tabular}{|c|c|c|c|c|c|c|c|c|}
\hline \multirow[b]{2}{*}{ Parity } & \multicolumn{2}{|c|}{$\kappa$-CNtot } & \multicolumn{2}{|c|}{$\mathrm{G}-\kappa \mathrm{CN}$} & \multicolumn{2}{|c|}{$\mathrm{U}-\kappa \mathrm{CN}$} & \multicolumn{2}{|c|}{ GD } \\
\hline & Est & HPD95\% & Est & HPD95\% & Est & HPD95\% & Est & HPD95\% \\
\hline 1 & $0.00^{\mathrm{a}}$ & & $0.00^{\mathrm{a}}$ & & $0.00^{\mathrm{a}}$ & & $0.00^{\mathrm{a}}$ & \\
\hline 3 & $0.02^{\mathrm{a}}$ & $-0.03,0.08$ & $0.14^{\mathrm{b}}$ & $0.07,0.22$ & $-0.13^{\mathrm{b}}$ & $-0.21,-0.05$ & $0.23^{\mathrm{b}}$ & $0.13,0.32$ \\
\hline$>3$ & $-0.07^{\mathrm{b}}$ & $-0.13,0.00$ & $0.05^{\mathrm{a}}$ & $-0.03,0.12$ & $-0.17^{\mathrm{bc}}$ & $-0.25,-0.10$ & $0.17^{\mathrm{b}}$ & $0.08,0.27$ \\
\hline
\end{tabular}

${ }^{\mathrm{a}-\mathrm{c}}$ Estimates within a column with different superscripts have a posterior probability greater than $95 \%$ of being different.

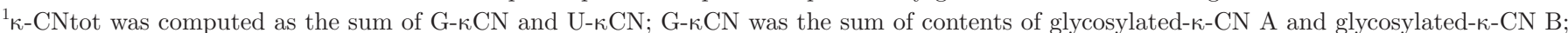

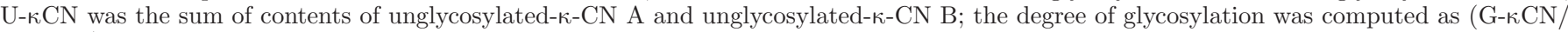
$\kappa$-CNtot) $\times 100$ 


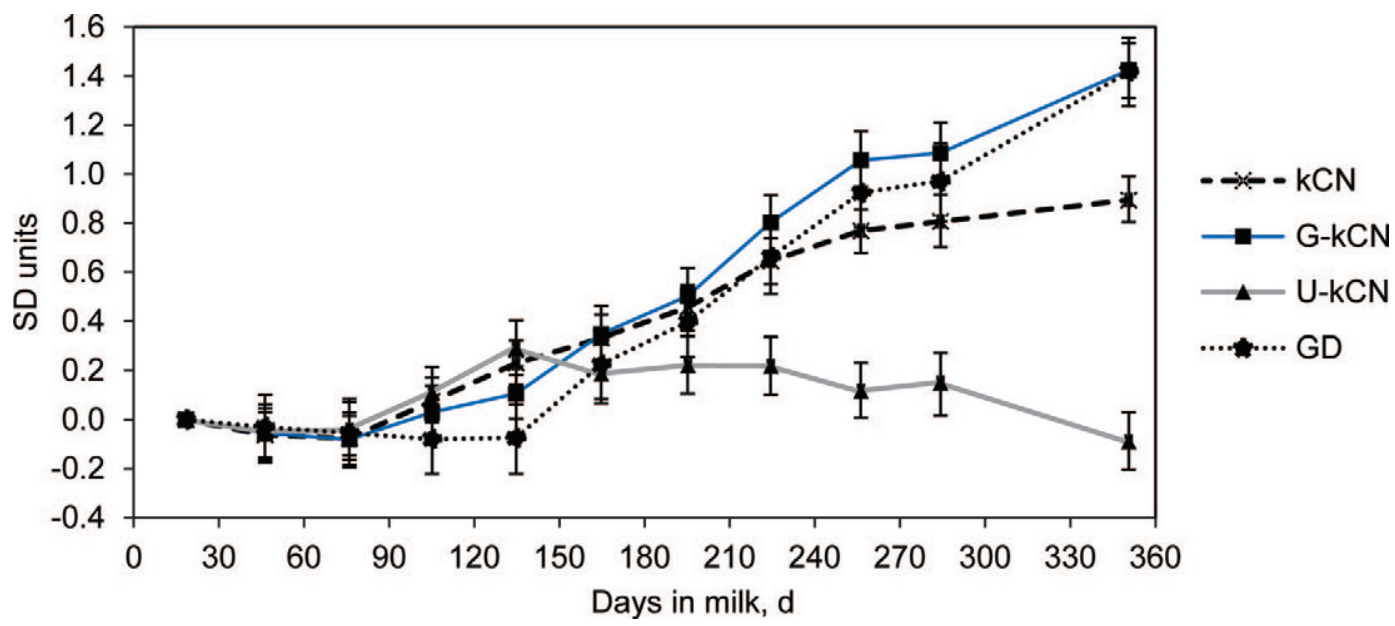

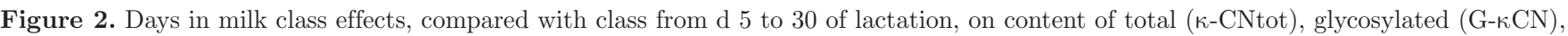
and unglycosylated $\kappa-\mathrm{CN}(\mathrm{U}-\kappa \mathrm{CN})$ and glycosylation degree (GD). Effects are measured in standard deviation units of each trait. Color version available in the online PDF.

\section{Effects of Milk Protein Genotypes on $\mathrm{k}$-CN Composition}

Estimates of the effects exerted by CSN2, CSN3, and $B L G$ genotypes on $\kappa-\mathrm{CN}$ composition are reported in Table 3. As expected, genotype CSN3 BB was associated with increased $\kappa$-CNtot compared with CSN3 AA. The increased $\kappa$-CNtot in milk of CSN $3 \mathrm{BB}$ cows can be ascribed to an increase in both $\mathrm{G}-\kappa \mathrm{CN}$ and $\mathrm{U}-\kappa \mathrm{CN}$. A slightly higher GD (0.17 SD units) was observed for CSN3 BB genotypes compared with CSN3 $\mathrm{AB}$ and CSN3 AA genotypes. Lodes et al. (1996) measured a greater proportion of unglycosylated $\mathrm{\kappa}-\mathrm{CN}$ in total protein for animals carrying $C S N 3 \mathrm{~B}$ than for those carrying CSN3 A. Conversely, Mariani et al. (1995) ascribed the increased $\kappa$-CNtot of $C S N 3 \mathrm{BB}$ exclusively to the increase in G-kCN. Although results of some studies (Dalgleish, 1986; Lodes et al., 1996; Jensen et al., 2012a) are inconsistent, several studies have reported significant associations between CSN3 B and increased NANA content (Robitaille et al., 1991; Mollé and Léonil, 1995; Coolbear et al., 1996), galactosamine content (Coolbear et al., 1996), or proportion of glycosylated fractions (Mariani et al., 1995; Coolbear et al., 1996; Jensen et al., 2012b). Such associations suggest a high efficiency of glycosylation for $\kappa-\mathrm{CN} B$ relative to $\kappa-\mathrm{CN}$ A. In comparison with $\kappa-\mathrm{CN} \mathrm{B}, \kappa-\mathrm{CN}$ A contains an additional site for glycosylation $\left(\mathrm{Thr}_{136}\right)$, but occurrence of proline-based turns makes this site less readily available for glycosylation than preferential sites $\mathrm{Thr}_{131}$ and $\mathrm{Thr}_{133}$ (Kumosinski et al., 1993). Robitaille et al. (1991) hypothesized that the substitution $\mathrm{Thr}_{136}(\mathrm{~A}) \rightarrow$ $\mathrm{Leu}_{136}$ (B) might change the conformation of the protein, making the glycosylation process more efficient.
Many factors affecting the efficiency of $\kappa-\mathrm{CN}$ glycosylation are still unknown and the role of those identified is often unclear.

Effects of genotypes at CSN2 and $B L G$ on variation in GD were small or trivial. Studies dealing with the effects of genes other than $C S N 3$ on variation in $\mathrm{G}-\kappa \mathrm{CN}$ and $\mathrm{U}-\kappa \mathrm{CN}$ are not available in the literature. All milk protein genes are known to affect variation in protein composition as a consequence of the differential expression of their genetic variants (Bonfatti et al., 2010b), and variation in $\kappa-\mathrm{CN}$ glycosylation might occur to cope with variations in the physicochemical properties of the micelles associated with milk protein polymorphisms.

\section{Heritability of $\mathrm{k}-\mathrm{CN}$ Composition}

Features of the marginal posterior densities for variance components and heritability of $\mathrm{k}-\mathrm{CN}$ fractions content and GD are reported in Table 4. The estimated heritability ranged from moderate to high for all investigated traits and was greater for $\mathrm{U}-\kappa \mathrm{CN}$ than for

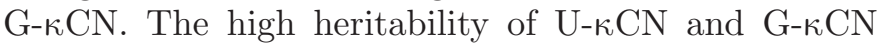
can be ascribed to the variation determined by milk protein genes. Caseins and $B L G$ genes were responsible for 82,55 , and $54 \%$ of the additive genetic variation in $\kappa$-CNtot, G- $\kappa \mathrm{CN}$, and $\mathrm{U}-\kappa \mathrm{CN}$, respectively. The estimated heritability of these traits decreased considerably when the linear model accounted for the effects of milk protein genes. Moreover, milk protein polymorphisms were expected to affect most of the variation in the single $\mathrm{k}$-CN fraction contents. The proportion of additive genetic variance explained by the effects of $C S N$ and $B L G$ genes was 57.4 and $54.4 \%$ for G- $\mathrm{kCN}$ and $\mathrm{U}-\kappa \mathrm{CN}$, respectively. The GD was highly heritable 
Table 3. Estimate (Est, SD units of the trait) and 95\% highest posterior density region (HPD95\%) of the effect of CSN2, CSN3, and BLG

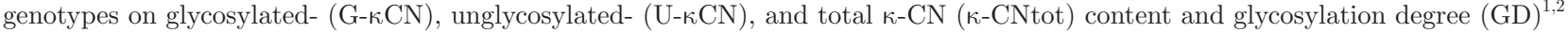

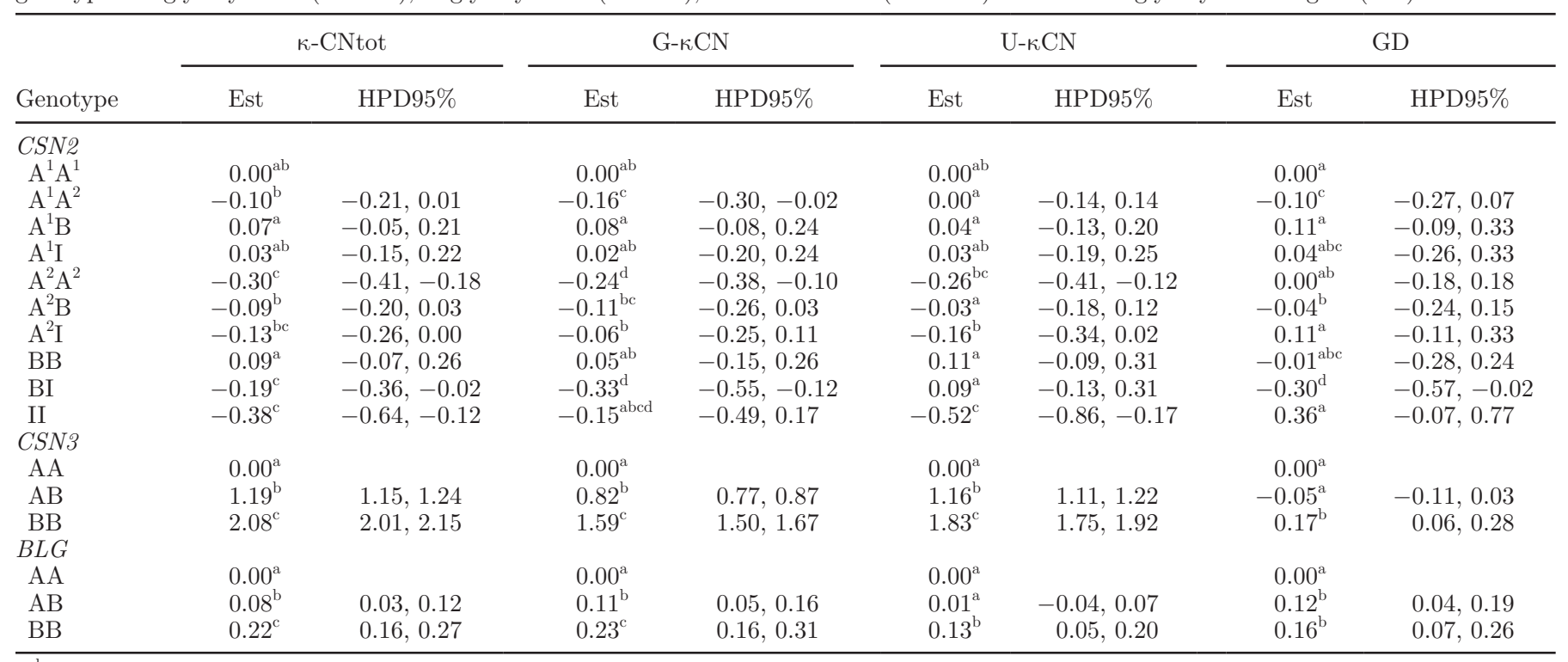

\footnotetext{
${ }^{\mathrm{a}-\mathrm{d}}$ Within a gene, estimates within a column with different superscripts have a posterior probability greater than $95 \%$ of being different.

${ }^{1}$ Genotypes CSN2 $\mathrm{A}^{1} \mathrm{~A}^{1}$, CSN3 $\mathrm{AA}$, and BLG AA were used as reference genotypes.

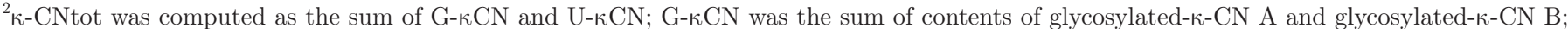

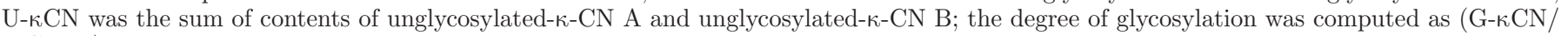
$\kappa$-CNtot) $\times 100$.

$\left(h^{2}=0.50 ; \mathrm{K} 95 \%=0.39 ; \mathrm{HPD} 95 \%: 0.37,0.64\right)$, but the effects of milk protein genes on GD variation were trivial. Variation in the extent of posttranslational modifications and GD is linked to genes encoding for the enzymes required for such modifications, such as SIAT $4 B$, a sialyltransferase catalyzing the last step of к-CN glycosylation (Tyrisevä et al., 2008). Although animal-related variation in the NANA content of $\kappa$-CN has been reported (Robitaille et al., 1991), the heritability of this trait or the content of specific $\kappa-\mathrm{CN}$ fractions has not been investigated in previous studies except

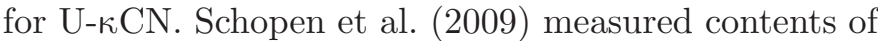
milk protein fractions by capillary zone electrophoresis, but they were able to quantify only the glyco-free portion of $\kappa-\mathrm{CN}$ (Heck et al., 2009) because the glycosylated $\kappa-\mathrm{CN}$ fraction co-eluted with $\beta-\mathrm{CN}$. In that study, the intra-herd heritability of the glyco-free $\kappa$-CN:total protein ratio was 0.64 .

\section{Effects of $\mathrm{K}$-CN Composition on MCP}

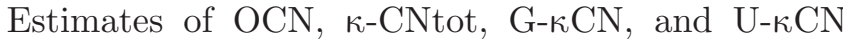
class effects on RCT and $\mathrm{Adj}_{30}$ are reported in Table 5. No relevant effect on RCT associated with variation in OCN was estimated by model [1]. Average RCT decreased when $\kappa$-CNtot increased. The estimated difference in RCT between the 2 extreme classes of $\kappa$-CNtot was $1.5 \mathrm{~min}$ (0.32 SD of the trait). To better elucidate the role of glycosylated and unglycosylated $\kappa-\mathrm{CN}$ fractions in MCP variation, an additional model (model [2]) that accounted for variation in $\mathrm{G}-\kappa \mathrm{CN}$ and $\mathrm{U}-\kappa \mathrm{CN}$ in place of the variation in the whole $\kappa$-CN fraction was fitted to the data. Rennet coagulation time was markedly affected by G- $\kappa \mathrm{CN}$. The effect of an increased G- $\kappa \mathrm{CN}$ was favorable and a difference in RCT between class $\mathrm{C}--$ and $\mathrm{C}++>2$ min ( $0.5 \mathrm{SD}$ of the trait) was detected. Conversely, the influence of $\mathrm{U}-\kappa \mathrm{CN}$ was less important and a small significant delay in the onset of coagulation was observed only when the content of this fraction was large (class $\mathrm{C}++$ ).

Differences in OCN and $\kappa$-CNtot were, to a great extent, responsible for variation in curd firmness. Adjusted $\mathrm{A}_{30}$ of $\mathrm{OCN}$ class $\mathrm{C}++$ was $0.72 \mathrm{SD}$ units greater than that of class $\mathrm{C}_{-}--$. Variation in $\operatorname{Adj}_{30}$ across $\mathrm{\kappa}$-CNtot classes was less intense, as indicated by an estimated difference between class $\mathrm{C}++$ and $\mathrm{C}--$ of 0.56 standard deviation units. Contributions of G- $\kappa \mathrm{CN}$ and $\mathrm{U}-\kappa \mathrm{CN}$ to the observed $\kappa$-CNtot effect on Adj $\mathrm{A}_{30}$ were similar: a difference in average $\operatorname{Adj}_{30}$ between class $\mathrm{C}++$ and $\mathrm{C}--$ of 2.1 (0.38 SD of the trait) and $1.98 \mathrm{~mm}(0.36 \mathrm{SD}$ of the trait) was detected for $\mathrm{G}-\kappa \mathrm{CN}$ and $\mathrm{U}-\kappa \mathrm{CN}$, respectively.

Associations between CSN3 B, high $\kappa$-CNtot, small size of the CN micelle, and enhanced milk coagulation have been described (Di Stasio and Mariani, 2000), but the effects of single $\kappa-\mathrm{CN}$ fractions on MCP have been 
rarely investigated. Chromosomal regions associated with noncoagulation of milk in Finnish Ayrshire include 2 potential candidate genes, a serine-threonine kinase on BTA2 and a sialyl transferase, which catalyzes the last step of $\kappa$-CN glycosylation, on BTA18 (Tyrisevä et al., 2008). This supports a role of $\kappa$-CN glycosylation in $\mathrm{MCP}$ variation, even though studies on the relationship between $\kappa$-CN glycosylation and MCP provide inconsistent results. Cases et al. (2003) estimated a favorable effect of $\kappa$-CN deglycosylation on acid coagulation of milk, with deglycosylated milk exhibiting gel formation at greater $\mathrm{pH}$ and increased gel stiffness compared with untreated milk. According to Robitaille et al. (1993) and Mariani et al. (1995), $\kappa$-CN glycosylation favorably affects both the rate of firming and the firmness of the curd, but its effects on coagulation time are trivial. Jensen et al. (2012b) described favorable effects of the glycosylated $\kappa$-CN fraction on rennet coagulation but, in a later study (Jensen et al., 2012a), detected no significant difference in the $\kappa$-CN posttranslational modification pattern between samples exhibiting good or poor coagulation properties.

Inconsistencies across studies arise from limited sample size, differences in definition of $\kappa$-CN glycosylation (e.g., quantification of NANA content or of glycosylated $\kappa-\mathrm{CN}$ ), differences in MCP assessment (e.g., acid or rennet coagulation, use of rheometer or Formagraph, analysis of whole or skim milk), or differences in the design of investigations (e.g., experimental or field conditions).

Results from this study indicate that variation in RCT attributable to $\kappa$-CNtot must be entirely ascribed to the glycosylated component of the protein. This is difficult to explain because the results obtained when investigating physicochemical modifications in $\mathrm{CN}$ micelles induced by $\kappa$-CN glycosylation were inconsistent. As an example, the rate of $\kappa$-CN cleavage by chymosin was independent of the amount of $\kappa$-CN-associated sugar in micelle suspensions obtained from milk ultrafiltrate (Dalgleish, 1986) or it was very low for the most glycosylated $\kappa$-CN when purified single fractions were compared (Doi et al., 1979b; Vreeman et al., 1986), or cleavage was incomplete for the unglycosylated $\kappa$-CN (Lieske and Valbuena, 2008).

Although the average size of the $\mathrm{CN}$ micelle is inversely related to $\kappa$-CNtot and good coagulation properties are associated with small micelles (Di Stasio and Mariani, 2000), G- $\kappa \mathrm{CN}$ has been reported to be positively associated (Dalgleish, 1986) or not associated (O'Connell and Fox, 2000) with micelle size.

The degree of $\kappa$-CN glycosylation is a key determinant of protein hydrophobicity (O'Connell and Fox, 2000), exhibiting a positive relationship with the size of the superficial hydrophilic layer of micelles. In addition, 
Table 5. Estimate (Est, SD units of the trait) and $95 \%$ highest posterior density region (HPD95\%) of glycosylated-k-CN (G- $\kappa \mathrm{CN}$ ), unglycosylated- $\kappa-\mathrm{CN}(\mathrm{U}-\kappa \mathrm{CN})$, total $\kappa-\mathrm{CN}$ ( $\kappa$-CNtot), and other caseins $\left(\alpha_{\mathrm{S1}^{-}} \mathrm{CN}, \alpha_{\mathrm{S} 2}-\mathrm{CN}, \beta-\mathrm{CN}\right.$, and $\gamma$-CN) content class effects, compared with the intermediate class $(\mathrm{C} 0)$, on rennet coagulation time $(\mathrm{RCT})$ and curd firmness adjusted for RCT $\left(\operatorname{Adj} \mathrm{A}_{30}\right)^{1,2}$

\begin{tabular}{|c|c|c|c|c|c|c|c|c|c|c|}
\hline \multirow[b]{2}{*}{ Trait } & \multirow[b]{2}{*}{ Effect } & \multicolumn{9}{|c|}{ Protein fraction class } \\
\hline & & Est & HPD95\% & Est & HPD95\% & $\mathrm{C} 0$ & Est & HPD95\% & Est & HPD95\% \\
\hline \multicolumn{11}{|l|}{$\mathrm{RCT}$} \\
\hline & Other caseins & -0.03 & $-0.12,0.06$ & 0.00 & $-0.08,0.07$ & 0 & 0.04 & $-0.05,0.13$ & 0.07 & $-0.02,0.16$ \\
\hline & $\kappa$-CNtot & $0.22^{\mathrm{a}}$ & $0.14,0.31$ & $0.08^{\mathrm{b}}$ & $0.00,0.16$ & $0^{\mathrm{c}}$ & $0.02^{\mathrm{bc}}$ & $-0.06,0.10$ & $-0.11^{\mathrm{d}}$ & $-0.20,-0.03$ \\
\hline \multirow{4}{*}{$\operatorname{Adj}_{30}$} & Other caseins & $-0.43^{\mathrm{a}}$ & $-0.52,-0.35$ & $-0.09^{\mathrm{b}}$ & $-0.17,-0.02$ & $0^{\mathrm{c}}$ & $0.18^{\mathrm{d}}$ & $0.10,0.26$ & $0.29^{\mathrm{e}}$ & $0.21,0.38$ \\
\hline & $\kappa-C N$ tot & $-0.37^{\mathrm{a}}$ & $-0.45,-0.29$ & $-0.22^{\mathrm{b}}$ & $-0.29,-0.14$ & $0^{\mathrm{c}}$ & $0.16^{\mathrm{d}}$ & $0.09,0.23$ & $0.19^{\mathrm{d}}$ & $0.11,0.27$ \\
\hline & $\mathrm{G}-\kappa \mathrm{CN}$ & $-0.28^{\mathrm{a}}$ & $-0.36,-0.19$ & $-0.17^{\mathrm{b}}$ & $-0.24,-0.10$ & $0^{\mathrm{c}}$ & $0.09^{\mathrm{d}}$ & $0.02,0.18$ & $0.11^{\mathrm{d}}$ & $0.03,0.20$ \\
\hline & $\mathrm{U}-\kappa \mathrm{CN}$ & $-0.16^{\mathrm{a}}$ & $-0.24,-0.09$ & $-0.10^{\mathrm{a}}$ & $-0.17,-0.02$ & $0^{\mathrm{b}}$ & $0.07^{\mathrm{c}}$ & $0.00,0.15$ & $0.20^{\mathrm{d}}$ & $0.12,0.28$ \\
\hline
\end{tabular}

\footnotetext{
${ }^{\mathrm{a} e}$ Estimates within a row with different superscripts have a posterior probability greater than $95 \%$ of being different.

${ }^{1}$ The content of other caseins was computed as the sum of $\alpha_{\mathrm{S}_{1}} \mathrm{CN}, \alpha_{\mathrm{S} 2}-\mathrm{CN}, \beta-\mathrm{CN}$ and $\gamma$-CN content; $\kappa$-CNtot was computed as the sum of

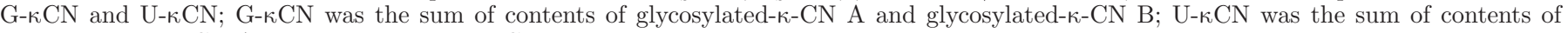

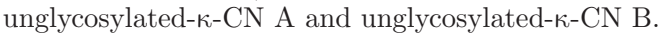

${ }^{2}$ Contents were classified as follows: class $\mathrm{C}--($ content $<$ mean $-\mathrm{SD})$, class $\mathrm{C}-($ mean $-\mathrm{SD} \leq$ content $<$ mean $-0.5 \mathrm{SD})$, class $\mathrm{C} 0$ : $($ mean $-0.5 \mathrm{SD} \leq$ content $<$ mean $+0.5 \mathrm{SD})$, class $\mathrm{C}+($ mean $+0.5 \mathrm{SD} \leq$ content $<$ mean $+\mathrm{SD})$, and class $\mathrm{C}++($ content $\geq$ mean $+\mathrm{SD})$.
}

each NANA residue adds a negative charge to the molecule (Fox and McSweeney, 2003). From a theoretical perspective, an increased degree of glycosylation is thus expected to stabilize the micelle structure (Dziuba and Minkiewicz, 1996) and to increase the time needed by chymosin to activate milk coagulation. However, there is no conclusive evidence that $\mathrm{\kappa}-\mathrm{CN}$ is a key element for stability of the native caseinate emulsions because understanding the stabilizing properties of $\kappa-\mathrm{CN}$ has been obtained for proteins isolated from micelles. Both $\alpha_{\mathrm{S1}^{-}}$and $\beta$-CN can, alone or in $\kappa$-CN-free mixtures, efficiently stabilize emulsions (Dalgleish, 1998). As a consequence, $\kappa$-CN does not seem to act simply as a hydrophobic surface-active material that emulsifies the rest of the caseins (Dalgleish, 1998).

\section{CONCLUSIONS}

Variation in the relative content of specific $\kappa-\mathrm{CN}$ fractions affects the behavior of milk during rennet coagulation, and the association between $\kappa$-CNtot and milk coagulation time is attributable exclusively to the glycosylated $\kappa-\mathrm{CN}$ fraction content. Exploitable additive genetic variation in the content of glycosylated $\kappa-\mathrm{CN}$ has been estimated, which makes enhancement of $\kappa$-CN composition through selective breeding an effective way to alter MCP. Further investigations are needed to elucidate the role of $\kappa$-CN glycosylation in variation in cheese yield and to identify genes affecting variation in the degree of $\kappa$ - $\mathrm{CN}$ glycosylation.

\section{ACKNOWLEDGMENTS}

The authors thank ANAPRI (Udine, Italy) for having provided pedigree information and AAFVG (Codroipo, Italy) and the milk recording agencies of Treviso, Vicenza, and Padova for organizing the milk sampling.

\section{REFERENCES}

Bonfatti, V., A. Cecchinato, G. Di Martino, M. De Marchi, L. Gallo, and P. Carnier. 2011. Effect of $\kappa$-casein B relative content in bulk milk k-casein on Montasio, Asiago, and Caciotta cheese yield using milk of similar protein composition. J. Dairy Sci. 94:602-613.

Bonfatti, V., G. Di Martino, A. Cecchinato, L. Degano, and P. Carnier. 2010b. Effects of $C S N 2-C S N 3$ haplotypes, BLG genotypes and detailed protein composition on coagulation properties of individual milk of Simmental cows. J. Dairy Sci. 93:3809-3817.

Bonfatti, V., G. Di Martino, A. Cecchinato, D. Vicario, and P. Carnier. 2010a. Effects of CSN2-CSN3 haplotypes and BLG genotypes on milk production traits, contents of protein fractions and detailed protein composition of individual milk of Simmental cows. J. Dairy Sci. 93:3797-3808.

Bonfatti, V., L. Grigoletto, A. Cecchinato, L. Gallo, and P. Carnier. 2008. Validation of a new reversed-phase high-performance liquid chromatography method for the separation and quantification of bovine milk protein genetic variants. J. Chromatogr. A 1195:101106.

Caroli, A. M., S. Chessa, and G. J. Erhardt. 2009. Invited review: Milk protein polymorphisms in cattle: Effect on animal breeding and human nutrition. J. Dairy Sci. 92:5335-5352.

Cases, E., V. Vidal, and J. L. Cuq. 2003. Effect of к-casein deglycosylation on the acid coagulability of milk. J. Food Sci. 68:2406-2410.

Cecchinato, A., and P. Carnier. 2011. Short communication: Statistical models for the analysis of coagulation traits using coagulating and non-coagulating milk information. J. Dairy Sci. 94:4214-4219.

Coolbear, K. P., D. F. Elgar, and J. S. Ayers. 1996. Profiling of genetic variants of bovine $\kappa$-casein macropeptide by electrophoretic and chromatographic techniques. Int. Dairy J. 6:1055-1068. 
Dalgleish, D. G. 1986. Analysis by fast protein liquid chromatography of variants of $\kappa$-casein and their relevance to micellar structure and renneting. J. Dairy Res. 53:43-51.

Dalgleish, D. G. 1998. Casein micelles and colloids: surface structures and stabilities. J. Dairy Sci. 81:3013-3018.

Di Stasio, L., and P. Mariani. 2000. The role of protein polymorphism in the genetic improvement of milk production. Zoot. Nutr. Anim. 26:69-90.

Doi, H., F. Ibuki, and M. Kanamori. 1979a. Interaction of א-casein components with $\alpha_{\mathrm{S} 1}$ and $\beta$-casein. Agric. Biol. Chem. 43:13011308

Doi, H., N. Kawaguchi, F. Ibuki, and M. Kanamori. 1979b. Susceptibility of $\kappa$-casein components to various proteases. J. Nutr. Sci. Vitaminol. (Tokyo) 25:33-41.

Dziuba, J., and P. Minkiewicz. 1996. Influence of glycosylation on micelle-stabilizing ability and biological properties of C-terminal fragments of cow's K-casein. Int. Dairy J. 6:1017-1044.

Fox, P. F., and P. L. H. McSweeney. 2003. Advanced Dairy Chemistry. Vol. 1. Kluwer Academic/Plenum Publisher, New York, NY.

Geweke, J. 1992. Evaluating the accuracy of sampling-based approaches to calculating posterior moments. Pages 169-193 in Bayesian Statistics 4. J. M. Bernardo, J. O. Berger, A. P. Dawid, and A. F. M. Smith, ed. Clarendon Press, Oxford, UK.

Heck, J. M., A. Schennink, H. J. van Valenberg, H. Bovenhuis, M. H. Visker, J. A. van Arendonk, and A. C. van Hooijdonk. 2009. Effects of milk protein variants on the protein composition of bovine milk. J. Dairy Sci. 92:1192-1202.

Holland, J. W., H. C. Deeth, and P. F. Alewood. 2004. Proteomic analysis of $\kappa$-casein micro-heterogeneity. Proteomics 4:743-752.

Holland, J. W., H. C. Deeth, and P. F. Alewood. 2005. Analysis of $O$-glycosylation site occupancy in bovine k-casein glycoforms separated by two-dimensional gel electrophoresis. Proteomics 5:9901002 .

Jensen, H. B., J. W. Holland, N. A. Poulsen, and L. B. Larsen. 2012a. Milk protein genetic variants and isoforms identified in bovine milk representing extremes in coagulating properties. J. Dairy Sci. 95:2891-2903.

Jensen, H. B., N. A. Poulsen, K. K. Andersen, M. Hammershøj, H. D. Poulsen, and L. B. Larsen. 2012b. Distinct composition of bovine milk from Jersey and Holstein-Friesian cows with good, poor, or noncoagulation properties as reflected in protein genetic variants and isoforms. J. Dairy Sci. 95:6905-6917.

Kumosinski, T. F., F. M. Brown, and H. M. Farrell Jr. 1993. Three dimensional molecular modeling of bovine caseins: A refined, energyminimized $\kappa$-casein structure. J. Dairy Sci. 76:2507-2520.
Lieske, B., and R. Valbuena. 2008. Variation in colloid-chemical status of casein micelles within influence on the chymosin coagulation properties of raw milk samples. Milchwissenschaft 63:247-250.

Lodes, A., J. Buchberger, J. Aumann, and H. Klostermeyer. 1996. The influence of genetic variants of milk proteins on the compositional and technological properties of milk: 1. Casein micelle size and the content of non-glycosylated kappa-casein. Milchwissenschaft 51:368-373.

Mariani, P., G. Zanzucchi, M. Masoni, P. Serventi, and M. Pecorari. 1995. Percentage distribution of caseins and the $\kappa$-casein fractions, separated by reverse-phase HPLC, in Italian Brown cows with different genotypes at the $\kappa$-casein locus. Sci. Tecn. Latt. Cas. 46:20-35.

Mollé, D., and J. Léonil. 1995. Heterogeneity of the bovine $\kappa$-casein caseinomacro-peptide, resolved by liquid chromatography on-line with electrospray ionization mass spectrometry. J. Chromatogr. A $708: 223-230$.

O'Connell, J. E., and P. F. Fox. 2000. The two-stage coagulation of milk proteins in the minimum of the heat coagulation time- $\mathrm{pH}$ profile of milk: Effect of casein micelle size. J. Dairy Sci. 83:378-386.

Robitaille, G., K. F. Ng-Kwai-Hang, and H. G. Monardes. 1991. Variation in the $N$-acetyl neuraminic acid content of bovine $\kappa$-casein. J. Dairy Res. 58:107-114.

Robitaille, G., K. F. Ng-Kwai-Hang, and H. G. Monardes. 1993. Effect of $\kappa$-casein glycosylation on cheese yielding capacity and coagulating properties of milk. Food Res. Int. 26:365-369.

Schopen, G. C. B., J. M. L. Heck, H. Bovenhuis, M. H. P. W. Visker, H. J. F. van Valenberg, and J. A. M. van Arendonk. 2009. Genetic parameters for major milk proteins in Dutch Holstein-Friesians. J. Dairy Sci. 92:1182-1191.

Takeuchi, M., E. Tsuda, M. Yoshikawa, R. Sasaki, and H. Chiba. 1985. Fractionation and characterization of 9 subcomponents of bovine к-casein A. Agric. Biol. Chem. 49:2269-2276.

Tyrisevä, A. M., K. Elo, A. Kuusipuro, V. Vilva, I. Janonen, H. Karjalainen, T. Ikonen, and M. Ojala. 2008. Chromosomal regions underlying noncoagulation of milk in Finnish Ayrshire cows. Genetics 180:1211-1220

Vreeman, H. J., S. Visser, C. J. Slangen, and J. A. Van Riel. 1986. Characterization of bovine kappa-casein fractions and the kinetics of chymosin-induced macropeptide release from carbohydrate-free and carbohydrate-containing fractions determined by high-performance gel-permeation chromatography. Biochem. J. 240:87-97. 